\title{
COMPENSAÇÃO AMBIENTAL: DA CONTRADIÇÃO À VALORAÇÃO DO MEIO AMBIENTE NO BRASIL
}

\section{Environmental compensation: from the contradiction to the valuation of the environment in Brazil}

\author{
Rafael Oliveira Fonseca \\ Universidade de São Paulo, São Paulo, São Paulo, Brasil \\ rafa.ofonseca@gmail.com
}

Artigo recebido em 23/08/2014 e aceito para publicação em 07/07/2015

RESUMO: Os debates acerca da temática ambiental revelam correntemente algumas contradições entre o desenvolvimento considerado sustentável e o modelo de crescimento econômico tradicional. No Brasil essa discussão é extremamente pertinente, dado que no território nacional de diversas formas manifestam-se algumas das contradições que envolvem demandas conjunturais por: crescimento econômico, proteção do meio ambiente e por um desenvolvimento sustentável. Nesse cenário, o Estado, como principal agente na dinâmica da gestão e no planejamento ambiental do território possui um papel primordial por meio da elaboração e execução de políticas públicas condizentes com esse propósito. Como atualmente o Estado (nos diversos níveis de governo) vem realizando maciços investimentos em setores considerados estratégicos para o crescimento econômico, o vetor ambiental vem sendo extremamente pressionado e cada vez mais valorado. Assim, neste contexto repleto de ações contraditórias, nosso artigo visa abordar alguns aspectos da compensação ambiental no Brasil, um instrumento da política ambiental vinculado ao processo de licenciamento ambiental que acaba por valorar o meio ambiente a partir da oneração dos empreendedores públicos ou privados em obras de significativo impacto ambiental.

Palavras-chaves: Meio Ambiente. Políticas Territoriais. Gestão Ambiental. Compensação Ambiental. Licenciamento Ambiental.

ABSTRACT: Debates about environmental issues commonly reveal some contradictions between sustainable development and the traditional model of economic growth. In Brazil this discussion is extremely relevant because in their territory in different ways are manifested some of the contradictions that involve situational demands for: economic growth, environmental protection and sustainable development. In this context, the state, as the main agent in the dynamics of management and environmental planning of the territory, has a key role through the development and implementation of public policies consistent with this purpose. As currently the state has been conducting massive investments in sectors considered strategic for economic growth, environmental vector has been extremely pressed and increasingly valued. Thus, in this replete context of contradictory actions, our paper aims to approach some aspects of environmental compensation/offset in Brazil, an instrument of environmental policy linked to the environmental licensing process, which ends up valuing the environment from the financial burden of entrepreneurs, public or private, in construction projects of significant environmental impacts.

Keywords: Environment. Territorial Policies. Environmental Management. Environmental Compensation. Environmental Licensing. 


\section{INTRODUÇÃO}

$\mathrm{Na}$ sociedade contemporânea, a temática ambiental está presente de diversas formas, sobretudo no que diz respeito aos aspectos relacionados à proteção do meio ambiente, à sua governança e ao desenvolvimento sustentável.

Apesar de examinada há séculos, se considerarmos a longa história da conservação ambiental, o debate ambiental adquiriu considerável amplitude na escala internacional após a Conferência de Estocolmo de 1972 (CNUMAH), sendo consequentemente objeto central de inúmeros encontros e pesquisas que nos anos subsequentes se tornaram cada vez mais correntes.

Em 1992 na Conferência do Rio de Janeiro (CNUMAD), o debate se fortaleceu e podemos dizer também que de certa forma se ampliou, pois foi a primeira reunião da $\mathrm{ONU}$ que permitiu a participação da sociedade civil organizada, mesmo que na qualidade de ouvinte, sem direito a voto e apenas alguns minutos de pronunciamento (RIBEIRO, 2001).

No início deste século XXI o tema continua a ocupar posição central no contexto internacional, dado as crescentes preocupações globais relacionadas às mudanças climáticas e a utilização dos recursos naturais, sendo caracterizado nos últimos anos por alguns avanços e impasses na regulação quanto ao acesso à biodiversidade e o controle das emissões de gases estufa (RIBEIRO e SANT'ANNA, 2012). Além disso, as mudanças climáticas previstas poderão gerar conflitos, sobretudo nas áreas mais pobres do planeta devido à escassez de recursos naturais (NORDAS e GLEDITSCH, 2007).

É patente que os seres humanos utilizem os recursos naturais para suprir suas necessidades, mas é preciso administrar o acesso aos mesmos, especialmente porque são raros em algumas situações e, além disso, estão disponíveis de forma não equilibrada, por isso a necessidade de gestão dos recursos naturais se impõe no período atual (RIBEIRO e SANT'ANNA, 2012).

Nesse complexo cenário, observa-se gradativamente a expansão e a consolidação do conceito de desenvolvimento sustentável, cada vez mais incorporado ao cotidiano e empregado de diversas formas e com diferentes interpretações, ainda que em alguns casos sejam similares. O conceito foi popularizado pelo Relatório Brundtland em 1987 como aquele desenvolvimento "(...) que atende as necessidades do presente sem comprometer a possibilidade das gerações futuras de atenderem as suas próprias necessidades" (CMMAD, 1991 [1987], p. 46).

Uma análise sobre o seu uso foi realizada apenas alguns anos após a publicação do Relatório (PEARCE; MARKANDYA; BARBIER, 1992 [1989]), sugerindo que apesar da falta de precisão de alguns autores, as ideias em relação ao conceito, de forma geral se correlacionam. Outros trabalhos realizaram análises mais críticas sobre o conceito como, por exemplo: Acselrad (1999), Frey (2001), Guimarães (2001), Sachs (2000 e 2004), Veiga (2005), Montibeller-Filho (2008) etc. Há ainda inúmeras outras definições similares, estabelecidas por pesquisadores de diversas áreas bem como por organizações e entidades internacionais como: Pnuma (Programa das Nações Unidas para o Meio Ambiente), UICN (União Internacional para a Conservação da Natureza), Banco Mundial, FMI (Fundo Monetário Internacional) etc.

Ainda que haja inúmeras definições, o uso do conceito de desenvolvimento sustentável é adotado com relativa frequência de forma a afrontar e questionar a efetividade do modelo de crescimento econômico tradicional, avaliado simplesmente pela demanda incessante de crescimento medido através apenas da variação do Produto Interno Bruto (PIB) dos países.

As inúmeras críticas ao conceito do PIB impulsionaram a ONU a criar o IDH (Índice de Desenvolvimento Humano), que considera diversos aspectos sociais, mas não os impactos ambientais (MARTINEZ-ALLER, 2007), dessa forma nenhuma listagem classificatória parece conseguir ocupar a lacuna que há dentre os inúmeros índices internacionais por não agregar satisfatoriamente os aspectos ambientais em conjunto com aspectos econômicos e sociais.

A despeito dessa problemática, o conceito de desenvolvimento sustentável se difundiu pelo mundo e logicamente também se propagou pelo Brasil, até 
por sua posição de destaque internacional.

Com uma dimensão territorial continental contemplada por um vasto litoral de milhares de quilômetros, o país possui uma imensa disponibilidade hídrica e é detentor de grande parte da maior floresta mundial, a Amazônia; possui uma abundante diversidade biológica dentre seus vários ecossistemas (sendo considerado por isso um dos Países Megadiversos), detém consideráveis riquezas minerais localizadas no continente e no mar, uma riqueza natural pouco conhecida e explorada dentro de sua Zona Econômica Exclusiva marítima, a Amazônia Azul, dentre outros notáveis elementos naturais.

No âmbito socioeconômico, o país possui uma população de 200 milhões de habitantes, o sétimo maior PIB mundial (BANCO MUNDIAL, 2014), se posiciona como um importante ator no comércio internacional de commodities agrícolas e minerais, concentra uma das maiores áreas do mundo dedicadas às atividades pecuárias, possui grandes extensões alagadas e outras com potencial de alagamento para geração de energia hidrelétrica, dentre outros fatores sociais e econômicos que trazem consequências ambientais extremamente nocivas e degradantes, sobretudo se não gerenciadas satisfatoriamente.

Dessa maneira, na atualidade o Brasil se situa como um protagonista internacional nas esferas econômica e ambiental. Portanto, possui destacada posição nas discussões atuais da ordem ambiental internacional (RIBEIRO, 2002), e não poderia ser diferente.

Por conter em sua jurisdição um relevante patrimônio natural e inúmeras atividades econômicas danosas ao meio ambiente, principalmente devido à exploração de seus recursos naturais, se manifestam no território brasileiro atualmente algumas das contradições que envolvem demandas conjunturais devido o crescimento econômico, a proteção do meio ambiente e também por um desenvolvimento sustentável. Para que toda essa demanda seja promovida o Estado possui um papel determinante por meio da elaboração e execução de políticas públicas condizentes com esse propósito.

Política pública, segundo a definição clássica, seria a própria ação da autoridade pública de forma que o Estado é visto por vezes como um organismo isolado da sociedade devido ao seu monopólio de gestão; por outro lado, o que está sendo observado na contemporaneidade é uma forma de política pública que emerge sem o monopólio do Estado (apesar desse ainda ser um ator importante e poderoso), buscando assim uma construção a partir de uma multiplicidade de atores, com interesses e demandas por vezes similares ou díspares, caracterizando-se como um modelo de ação policêntrico (MASSARDIER, 2003).

Nesse complexo e por vezes contraditório cenário, atualmente no Brasil o Estado (nos diversos níveis de governo) vem realizando maciços investimentos em setores considerados estratégicos para o crescimento econômico (principalmente transportes, energia e infraestrutura urbana), dessa maneira o vetor ambiental vêm sendo pressionado e cada vez mais valorado. Nesta análise consideramos que o termo valorar significa analisar (algo) a fim de atribuir-lhe valor ou julgamento (HOUAISS, 2009).

Assim, este artigo visa apresentar a compensação ambiental no Brasil, um instrumento da política ambiental do país vinculado ao processo de licenciamento ambiental que acaba por valorar o meio ambiente a partir da oneração dos empreendedores em obras de significativo impacto ambiental.

\section{O Estado na encruzilhada entre o crescimento econômico e a proteção ambiental}

O Estado é o principal agente da dinâmica de gestão e do planejamento ambiental no território. Falar do meio ambiente é tratar indissociavelmente do território, da mesma forma que falar de política é tratar de seus vínculos com a sociedade e esse agente assim como as relações de poder existentes (MELLO-THÉRY, 2011), passando por todas as organizações que acabam por "produzir" o território; certamente o Estado, a partir de suas políticas, está sempre organizando o seu território (RAFFESTIN, 1993 [1980]).

Nesse contexto de relações de poder e interesses, observamos há algumas décadas, sobretudo no decorrer dos anos de 1990, o ingresso do Brasil em um processo de alterações políticas e econômicas caracterizado, dentre outros fatores, pela adoção de um modelo de desenvolvimento 
fundamentado na abertura da economia em relação ao mercado internacional.

Esse processo iniciado no Governo Collor (1990-1992), teve como principal justificativa a falência do projeto desenvolvimentista até então em vigor no Brasil (FURTADO, 1959; BRESSERPEREIRA, 1975 [1968]; BIELSCHOWSKY, 1995). A argumentação governamental na época era a existência de uma baixa qualidade dos setores de serviços estatais sem concorrentes e dos produtos industriais nacionais que eram protegidos por altas barreiras alfandegárias, sendo utilizados como exemplos da incapacidade do governo de atuar como administrador até então. Observou-se uma crescente abertura comercial, o início da privatização de setores considerados estratégicos para desenvolvimento do país, a busca de uma estabilidade monetária e um controle sobre a inflação visando impulsionar o país economicamente, no contexto da globalização, a atrair investidores estrangeiros e consequentemente aumentar as exportações e sua inserção no mercado mundial.

Esse modelo acabou por impor ao país um novo padrão de organização do território baseado, por exemplo, na busca de uma maior eficiência infraestrutural em setores considerados estratégicos para o crescimento econômico do país, visando ampliar e intensificar a inserção gradativa do país no mercado cada vez mais mundializado. Para Sposito (1999), essa mundialização expressa a tendência de expansão das relações capitalistas de produção e a sua capacidade de buscar impô-las em todos os lugares do mundo, através da financeirização das relações econômicas e da formação de redes de comunicações mundiais.

De forma concomitante as essas alterações internas, o país participou ativamente das discussões ambientais internacionais, tendo o governo da época atuado como um importante articulador para a realização em 1992 da ECO-92 (CNUMAD), cúpula que consagrou o conceito de desenvolvimento sustentável, produziu a Agenda 21, dentre outros acordos e diretivas internacionais ambientais.

Assim, estabelece-se de forma aparentemente irreversível a concepção de que para ser sustentável o desenvolvimento deve ser: economicamente sustentado (ou eficiente), socialmente desejável (ou includente) e ecologicamente prudente (ou equilibrado) (SACHS, 2004; ROMEIRO, 2012).

Apesar disso, surge uma grande dificuldade no enfrentamento entre a expansão econômica e a conservaçãodomeioambiente(MARTINEZ-ALLER, 2007), pois dentre todos os problemas enfrentados pelo sistema mundial, a degradação ambiental talvez seria o mais intrinsecamente transnacional, podendo ser dessa maneira a plataforma para um exercício de solidariedade transnacional e também intergeracional (SANTOS, 1995).

Da mesma maneira que a causa ambiental se expandiu, o crescimento econômico também atingiu espaços cada vez mais amplos no mercado global. As alterações pós-1990 contribuíram para uma intensa divisão territorial do trabalho em escala mundial e a busca constante por uma maior racionalidade infraestrutural na maior parte do mundo. Nesse sentido, consideramos que o conceito de infraestrutura corresponde ao conjunto de estruturas e atividades de um país (instalações, equipamentos físicos, estruturas organizacionais e institucionais), ou fundações econômicas e sociais que servem de base para o desenvolvimento de outras atividades (PINTO JÚNIOR, 2010).

Pode-se dizer que esse cenário acabou por promover uma conjuntura na qual a circulação, material e imaterial, reforçou seu papel como elemento intrínseco e indissociável dos processos produtivos, ocasionando um relevante crescimento na demanda nos setores de transportes e comunicações. O crescimento econômico ocasionou também o aumento da demanda por energia elétrica, por isso estima-se que a capacidade instalada no Sistema Elétrico Interligado Nacional (SIN) do Brasil deve evoluir de cerca de 110 gigawatts (2010) para 171 gigawatts (2020), com a priorização de fontes renováveis como hidráulica, eólica e biomassa (TOLMASQUIN, 2012).

Em vista disso, nos últimos anos foram realizadas no Brasil grandes obras infraestruturais conduzidas pelo Estado nos setores de transportes e energia, na sua maioria fruto do planejamento plurianual do segundo mandato do Governo Lula que 
resultou no Programa de Aceleração do Crescimento (PAC), realizado entre 2007 e 2010, bem como aquelas que estão sendo realizadas pelo atual Governo Dilma Rousseff, a partir do Programa de Aceleração do Crescimento 2 (PAC2), em execução de 2011 a 2014.

O PAC foi dividido em três grandes eixos (Energia, Logística e Infraestrutura Social e Urbana) com investimentos de $\mathrm{R} \$ 542,8$ bilhões até dezembro de 2010, além de outros $\mathrm{R} \$ 115,6$ bilhões previstos para pós-2010 (BRASIL, 2010). Já o PAC2, em execução, é dividido seis eixos (Transportes, Energia, Cidade Melhor, Comunidade Cidadã, Minha Casa Minha Vida, Água e Luz para todos) e teve até 30/04/2014 investimentos da ordem de R\$ 871,4 bilhões o que representa $84,6 \%$ do previsto pelo Programa (BRASIL, 2014).

Essa conjuntura de expansão das infraestruturas voltadas ao crescimento econômico passa a reproduzir no país questionamentos e pressões vinculadas aos valores e parâmetros disseminados e definidos nos acordos e convenções internacionais ambientais. A sociedade, de forma geral, passa a exigir posições do Estado em relação à proteção dos recursos naturais e, ao mesmo tempo, busca transformar esses recursos em produtos de mercados, ou seja, exige simultaneamente uma forte política de preservação, bem como de inserção do país no mercado global; que são dois aspectos contraditórios (MELLO, 2006).

É nesse sentido que o desenvolvimento, compreendido como um processo intencional e autodirigido de transformação e gestão das estruturas socioeconômicas visando assegurar a todas as pessoas oportunidades de bem-estar e de uma vida plena e gratificante, poderia apresentar uma definição mais completa adicionando-o o adjetivo "integral" ou "total", abarcando todas as facetas pertinentes ao desenvolvimento (SACHS, 2007).

De qualquer maneira, nas contradições existentes acerca de como obter o famigerado crescimento, as políticas públicas ambientais se inserem em um campo de forças repleto de posições conflitantes sobre as questões econômicas, políticas, institucionais, ecológicas e sociais. Por vezes, o discurso do crescimento econômico a qualquer custo pressiona a proteção da diversidade biológica a tal ponto que a não realização de um empreendimento é considerada um prejuízo à coletividade (BECHARA, 2009), revelando novamente essa discrepância cada vez mais evidente nos dias atuais.

No cerne dessa contradição há vários elementos relevantes, como os danos ambientais causados pelas grandes obras infraestruturais dirigidas pelo Estado (nos diversos níveis de governo conforme mencionamos), que frequentemente causam amplos debates devido à magnitude dos seus impactos e a incapacidade estrutural de monitoramento por parte de alguns órgãos estatais, apesar da existência no Brasil da avaliação de impacto ambiental (AIA) juntamente com o licenciamento ambiental.

Em função do ordenamento jurídico adotado no país a AIA e o licenciamento ambiental acabaram por se estabelecerem de forma vinculada e são por vezes confundidos como um mesmo instrumento de gestão ambiental.

A AIA pode ser compreendida como um conjunto de procedimentos de natureza técnicocientífica e administrativa, com o objetivo de analisar os impactos ambientais de um projeto e assegurar que os resultados dessa análise influenciem nas decisões que o envolvem (MOREIRA, 1989). No Brasil se estabeleceu a partir da Política Nacional do Meio Ambiente de 1981 na figura do licenciamento ambiental, sendo posteriormente fortalecida pela Constituição de 1988 (SÁNCHEZ, 2008).

Já o licenciamento ambiental (LA) é um instrumento da política ambiental capaz de formalizar o papel antecipatório do empreendedor, garantindo aos possuidores das licenças o reconhecimento público de que suas atividades serão realizadas com a perspectiva de promover a qualidade ambiental e sua sustentabilidade (IBAMA, 2002). Ao emitir licenças o Estado busca controlar as atividades que possam interferir nas condições ambientais do território.

Assim, para cumprirem suas metas, gradativamente os países signatários dos principais acordos internacionais passam a estabelecer ações públicas e leis visando à redução dos impactos ambientais ocasionados pelas atividades econômicas, através, por exemplo, do licenciamento ambiental, em reação muitas vezes às exigências das principais 
instituições financeiras concessoras de crédito, como: Banco Interamericano de Desenvolvimento (BID), Banco Mundial (Bird), Banco Nacional de Desenvolvimento Econômico e Social (BNDES), Banco do Brasil, Caixa Econômica Federal, dentre outros.

De qualquer maneira, apesar das pressões mundiais, a soberania sobre os recursos naturais ainda ocupa posição relevante nos Estados (PAQUEROT, 2005), o que dificulta por vezes a execução de alguns acordos e objetivos internacionais.

No Brasil, os primeiros estudos ambientais foram preparados para o setor hidrelétrico durante os anos 1970, como reflexo dessa influência internacional e de algumas experiências negativas. Foi nessa década que durante o regime militar iniciou-se a construção da Usina Hidrelétrica de Balbina sem a devida atenção para seus impactos ambientais. Balbina acabou por se tornar uma referência negativa de planejamento estatal, devido seu alto impacto sobre o meio ambiente, bem como pelo baixo potencial de geração de energia elétrica, o que posteriormente contribuiu para adoção de estudos mais rígidos acerca dos impactos ambientais de grandes obras infraestruturais.

Além disso, as influências estrangeiras acabam por estimular uma dinâmica que possibilita o estabelecimento de políticas ambientais que devem ser estabelecidas transversalmente perpassando pelas demais políticas (PAGNOCCHESCHI e BERNARDO, 2006). Essa transversalidade é um desafio, pois envolve os interesses de inúmeros atores e mudanças de práticas consolidadas há décadas ou séculos (LITTLE, 2003) e, por vezes, alguns interesses econômicos procuram inviabilizála, criando obstáculos para promoção de uma política ambiental integrada para o desenvolvimento sustentável (VIEIRA e CADER, 2013).

Conforme destaca Veiret e Richemond (2007), a relação do território com o risco tem variado de acordo com a época, e os riscos justificam as escolhas políticas pelo viés das regulamentações. Nesse sentido, um importante instrumento que contribui para a promoção da política ambiental no Brasil é a compensação ambiental.

\section{A compensação ambiental e a valoração do meio ambiente}

A compensação ambiental pode ser definida como um instrumento da política ambiental pública que visa contrabalançar os impactos ocorridos ou previstos no processo de licenciamento ambiental de empreendimentos de construção civil com significativos impactos ambientais, fundamentados em estudo de impacto ambiental e respectivo relatório (EIA/RIMA), onerando os empreendedores com o objetivo de compensar os impactos não mitigáveis causados.

O EIA é um documento de natureza técnica que tem como objetivo avaliar os impactos ambientais gerados por todas as atividades e/ou empreendimentos potencialmente poluidores e/ou que possam causar degradação ambiental, contemplando a proposição de medidas mitigadoras e de controle ambiental. $\mathrm{O}$ RIMA, como relatório respectivo, deve refletir as conclusões do EIA e tem o objetivo de promover publicidade e portanto informar à sociedade sobre os impactos, medidas mitigadoras e programas de monitoramento do empreendimento ou atividade, sendo apresentado de forma a facilitar a compreensão em uma linguagem simples, objetiva e acessível (MMA, 2009).

O instrumento da compensação ambiental surgiu no Brasil, como um componente da AIA, associado aos grandes projetos do setor elétrico brasileiro, em especial àqueles situados na Amazônia, como uma forma de criação de áreas voltadas à conservação da biodiversidade nas regiões afetadas por esses grandes empreendimentos (FARIA, 2008).

Para Born e Talocchi (2002), as compensações ambientais são instrumentos econômicos de remuneração realizados devido à existência de efeitos danosos, como impactos negativos e não mitigáveis decorrentes das atividades antrópicas diversas. Para Sánchez (2008), seria uma forma de "substituição" equivalente de um bem ambiental que será perdido, alterado ou descaracterizado, e não deve ser confundidas como uma indenização, que é um pagamento em espécie pela perda de um bem.

O Instituto Chico Mendes da Biodiversidade (ICMBio), órgão ambiental estatal, define a 
compensação ambiental como um instrumento de política pública que, intervindo junto aos agentes econômicos, proporciona a incorporação dos custos sociais e ambientais da degradação gerada por determinados empreendimentos, em seus custos globais (ICMBIO, 2014).

Vale destacar que os termos "compensação ambiental" e "medidas compensatórias" são utilizados, com frequência, de forma indiscriminada gerando confusões que acarretam em equívocos comuns. Medidas compensatórias são aquelas ações que visam compensar impactos ambientais negativos irreversíveis e inevitáveis, distinguindo-se das denominadas medidas mitigadoras que são ações destinadas a prevenir impactos adversos ou a reduzir aqueles que não podem ser evitados (FARIA, 2008).

$\mathrm{Na}$ legislação brasileira, a compensação ambiental foi abordada inicialmente pelo Conama (Conselho Nacional do Meio Ambiente) em 1987 por meio da Resolução 10, que exigia das obras de grande porte a implantação de Estações Ecológicas como contrapartida. A fixação do montante de recursos deveria ser proporcional ao dano a se ressarcir, no valor não inferior a $0,5 \%$ do custo de implantação do empreendimento (GIASSON e CARVALHO, 2012).

É nesse sentido que o meio ambiente passa a ser valorado, ao se estabelecer que o empreendedor deveria dispor de um montante equivalente a $0,5 \%$ do investido em seu empreendimento para contrabalançar os impactos causados pelo mesmo. A definição desse percentual gera amplas discussões que envolvem a questão de como valorar financeiramente os impactos causados por empreendimentos, acarretando em um imbróglio jurídico que até hoje está em trâmite no Brasil.

A atribuição de valores aos ativos ambientais é um debate extremamente complexo e, de forma geral, um ativo da biodiversidade somente tem valor quando sua utilidade é imprescindível para a vida na Terra (MOTA et al, 2010). Todo recurso ambiental tem um valor intrínseco e do ponto de vista econômico, o valor de um recurso ambiental é o valor para a tomada de decisão, ou seja, é a contribuição do recurso para o bem-estar social (ORTIZ, 2003).

No cerne desta discussão, a compensação ambiental foi estabelecida como lei no ano 2000
(Lei $\mathrm{n}^{\circ}$ 9.985/2000, art. 36) a partir do Sistema Nacional de Unidades de Conservação da Natureza (SNUC), mantendo-se o mínimo de $0,5 \%$ do custo de implantação do empreendimento. Logo em seguida, em 2002, as diretrizes que tratam do instrumento foram expressas pela primeira vez no Decreto $n^{\circ} 4.340 / 2002$ regulamentador da Lei do SNUC, mantendo-se o mesmo percentual mínimo sem novamente prever a fixação de um valor máximo.

Por isso, no final de 2004 a Confederação Nacional das Indústrias (CNI) ajuizou a Ação Direta de Inconstitucionalidade (ADI) $\mathrm{n}^{\circ} 3.378$, com o objetivo de impugnar o artigo 36 da Lei do SNUC e seus parágrafos $1^{\circ}, 2^{\circ}$ e $3^{\circ}$, alegando que esses dispositivos feririam os princípios da legalidade, da separação de poderes, da razoabilidade e da proporcionalidade (DOMINGUES e CARNEIRO, 2010). As questões centrais dessa ação estão relacionadas ao fato da Lei do SNUC não fixar um percentual máximo para a definição da compensação ambiental pelo órgão ambiental licenciador, além da mesma estar vinculada ao custo total do empreendimento.

Posteriormente em 2005, o Decreto regulamentador do SNUC foi alterado (através do Decreto $n^{0} 5.566 / 2005$ que alterou o art. 31 do Decreto $\mathrm{n}^{\circ} 4.340 / 2002$ ), mas não houve qualquer mudança no que se refere ao percentual da compensação ambiental. Até que em 2006, o Tribunal Regional Federal da $1^{\text {a }}$ Região concedeu liminar (Agravo de Instrumento $\mathrm{n}^{\mathrm{o}}$ 2005.01.00.060479-0/DF) limitando como valor máximo para a aplicação do percentual da compensação ambiental $0,5 \%$ para todos os empreendimentos considerados de significativo impacto ambiental.

Dois dias depois o Ibama, órgão ambiental federal, ajuizou no Superior Tribunal Federal (STF) uma Suspensão de Segurança ( $\left.\mathrm{n}^{\circ} 2.875\right)$ considerando legítima a fixação de um percentual mínimo e a ocorrência de grave lesão à ordem e à economia pública (DOMINGUES e CARNEIRO, 2010). Suspensão de Segurança é um pedido feito ao presidente do STF para que seja cassada liminar ou decisão de outros tribunais, em única ou última instância, em mandado de segurança, só podendo ser concedida, por meio de despacho fundamentado, nos casos de lesão à ordem, à saúde, à segurança e à economia pública (STF, 2014). 
Logo em seguida, no mesmo ano, o Conama publicou a resolução 371/2006, fixando em seu artigo 15 o valor da compensação ambiental em exatos $0,5 \%$, tornando-a invariável até que o órgão ambiental licenciador (Ibama) elaborasse metodologia de cálculo para definição do grau de impacto ambiental.

Em 2008, o STF analisou a ADI e julgou parcialmente precedente a ação declarando inconstitucional a expressão prevista na Lei do SNUC que define o valor da compensação no mínimo de $0,5 \%$ dos custos totais do empreendimento, dessa forma, o percentual deverá ser fixado proporcionalmente ao impacto ambiental sem vínculo ao custo total do empreendimento, tendo como base o EIA/RIMA.

Por fim, um ano após a decisão do STF foi publicado o Decreto $n^{0} 6.848 / 2009$ alterando os artigos 31 e 32 do Decreto $n^{\circ} 4.340 / 2002$ regulamentador do SNUC. Dessa maneira ficou definido que o Ibama deve estabelecer o grau de impacto de um empreendimento para fins da compensação ambiental considerando os impactos negativos sobre o meio ambiente tendo como base o respectivo EIA/RIMA, ademais de outros detalhes definidos nos parágrafos do referido artigo.
Este último Decreto instituído inovou ao definir em seu Anexo a Metodologia de Cálculo do Grau de Impacto Ambiental, que é utilizada atualmente para definir o grau de impacto (GI) de um empreendimento e, consequentemente, qual o valor da compensação ambiental a ser despendido pelo empreendedor tendo como base o valor de referência (VR). OVRé o somatório dos investimentos necessários para implantação do empreendimento, não incluídos os investimentos referentes aos planos, projetos e programas exigidos no procedimento de licenciamento ambiental para mitigação de impactos causados pelo empreendimento, bem como os encargos e custos incidentes sobre o financiamento do empreendimento, inclusive os relativos às garantias, e os custos com apólices e prêmios de seguros pessoais e reais.

A atual metodologia delimita o grau de impacto (GI) entre $0 \%$ e $0,5 \%$ (art. 31-A) considerando as informações disponíveis no EIA/RIMA e possuem como referência para a avaliação os impactos sobre a biodiversidade, o comprometimento de áreas prioritárias e a influência em unidades de conservação, além de alguns índices pré-estabelecidos (Figura 1).

Figura 1- Metodologia de cálculo da compensação ambiental

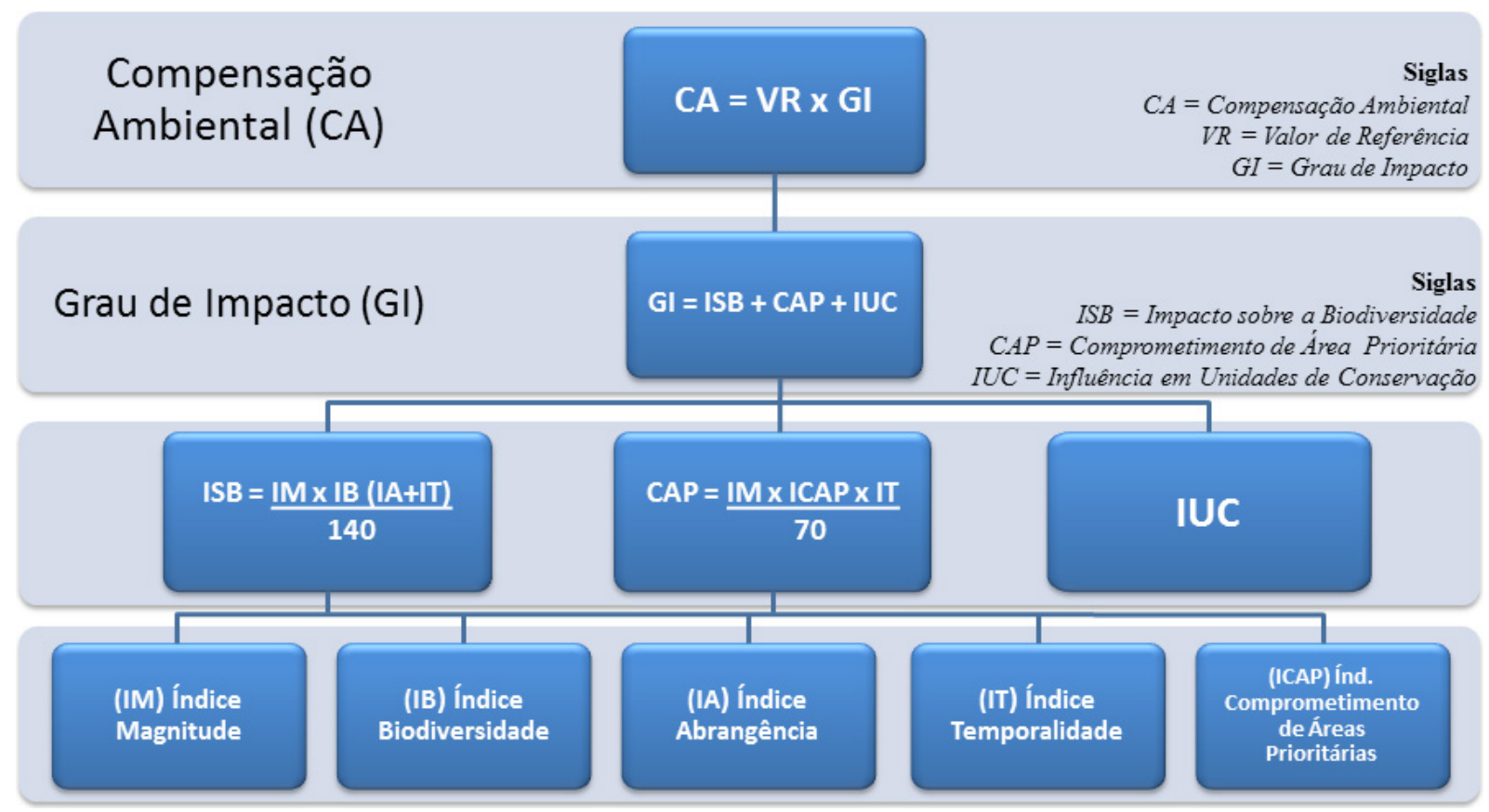

Fonte: organização do Autor com base no Anexo do Decreto n ${ }^{\circ} 6.848 / 2009$

(Decreto disponível em: http://www.planalto.gov.br/ccivil_03/_Ato2007-2010/2009/Decreto/D6848.htm) 
Os cincos Índices (IM, IB, IA, IT e ICAP) necessários para o cálculo do GI devem ser estabelecidos pelos EIA/RIMA dos empreendimentos em processo de licenciamento ambiental. O Anexo do Decreto de 2009, em seu item 2, detalha a variação de todos os índices bem como seus respectivos atributos. Para tanto, destacamos que os índices IM, IB e ICAP variam de 0 a 3 , e os índices IA e IT variam de 1 a 4 .

Assim, enfatizamos que cabe ao órgão ambiental licenciador (IBAMA) realizar o cálculo da compensação ambiental de acordo com as informações disponíveis no EIA/RIMA, avaliando a objetividade da mensuração dos índices necessários para o respectivo cálculo, assim como outras informações necessárias e disponibilizadas pelo empreendedor.

Segundo Domingues e Carneiro (2010), o Decreto $\mathrm{n}^{\circ} 6.848 / 2009$ ao delimitar o valor da compensação ambiental entre $0 \%$ e $0,5 \%$ tendo como base o valor de referência (VR), estabelece uma afronta à decisão do STF que declarou inconstitucional a noção de custo total do empreendimento e a referência ao percentual. Além disso, o Decreto em vigor apenas dissimula os critérios julgados inconstitucionais, mas de qualquer maneira ao elaborar uma metodologia de cálculo foram minimizadas as inseguranças jurídicas causadas anteriormente pelo instrumento ambiental.

Ademais, conforme abordamos anteriormente, pela atual metodologia nenhum empreendimento ultrapassará o percentual de $0,5 \%$, abrandando as inseguranças dos empreendedores em relação ao fato da legislação anteriormente em vigor não fixar um percentual máximo a ser atribuído à compensação ambiental. Por outro lado, deixa evidente que, ao menos para esse instrumento, o valor do meio ambiente nunca será maior que $0,5 \%$ do total a ser investido por um empreendedor, algo extremamente questionável.

Nesse imbróglio que exacerba as relações de poder e interesses do Estado e da iniciativa privada não podemos esquecer que há ainda outros importantes atores, como por exemplo, algumas organizações da sociedade civil. Nesse sentido, em junho de 2009 o Instituto Socioambiental (ISA) e a ONG Amigos da Terra protocolaram a Reclamação $\mathrm{n}^{\circ} 8.465$ alegando que o Decreto 6.848/2009 afronta a decisão do STF (ISA, 2014).
De acordo com a petição apresentada, ao se impor um montante máximo para a compensação estará desestimulando as empresas a investirem em tecnologias que, mesmo sendo possivelmente mais onerosas, sejam mais afáveis ao meio ambiente, os empreendedores saberão que isso encarecerá o valor da obra que volta a ser o fator indexador da compensação ambiental. Nessa lógica, quanto mais 'sujo' o empreendimento, mais barato ele será, e, consequentemente, menor será também o valor da compensação, muito embora o impacto causado venha a ser proporcionalmente maior (ISA, 2014).

Do ponto de vista das ONGs, o valor da compensação ambiental, para estar de acordo com a decisão do STF, deve ser baseado no impacto ambiental previsto e não no valor do empreendimento, ou seja, neste imbróglio ainda parece distante o encontro de uma resolução que atenda todas as demandas desse cenário contraditório e conflituoso.

\section{CONSIDERAÇÕES FINAIS}

O Estado e suas políticas públicas possuem papel preponderante frente às numerosas demandas associadas à temática ambiental que emanam desde o âmbito global até as mais tênues e sutis especificidades locais dos territórios; no Brasil isso não é diferente.

Com a consolidação da ação ambiental por parte da sociedade civil organizada, bem como com a expansão das instituições e agências ambientais governamentais, o conceito de política pública se redefiniu como um conjunto de decisões interrelacionadas, determinado por atores políticos, com a finalidade de ordenar, regular e controlar o bem público. Nesse contexto, o vetor socioambiental acaba então por assumir um papel cada vez mais relevante na organização dos territórios, sobretudo quando as ações públicas gradativamente se tornam policêntricas, e o conceito de público incorpora não somente o Estado, mas também a sociedade civil e o setor privado (LITTLE, 2003).

As relações de poderes e interesses entre todas as partes são exacerbadas na maior parte dos países no momento em que a prioridade quase sempre é o crescimento simplesmente econômico e, muitas vezes, a proteção ambiental é considerada um entrave para 
esse objetivo. A produção de mercadorias em escala global é uma forma de pressionar pelo aumento do uso dos recursos naturais, por isso a gestão dos recursos naturais e da questão ambiental se impõe (RIBEIRO e SANT'ANNA, 2012).

Nesse cenário intrincado e por vezes contraditório temos no Brasil a compensação ambiental, um instrumento controverso e, por vezes considerado como pouco compreendido, mesmo entre profissionais relacionados ao setor socioambiental. Além disso, muitos setores não possuem o interesse de ampliar a sua compreensão, sendo objeto de numerosas críticas que o revestem de um sofisma concebido por argumentos de retardar o desenvolvimento econômico do país, sobretudo por dois motivos.

Primeiro, por possuir uma gestão estatal falha em relação à gestão e a fiscalização, geralmente com adoção de medidas desgovernadas pelos órgãos ambientais tornando o licenciamento ambiental passível de diferentes interpretações, sendo alvo de descrença em relação a possíveis punições legais.

Segundo, pela ausência de transversalidade das políticas públicas; frequentemente medidas díspares são adotadas, às vezes simplesmente inviabilizando empreendimentos sob o argumento da proteção do meio ambiente, em outros momentos licenciando projetos sem a devida atenção ambiental, tornando a emissão de licenças um instrumento que se aplica com interesses distintos.

Um licenciamento ambiental realizado sem os devidos critérios técnicos visando soluções mais rápidas e econômicas em curto prazo deixa para o futuro os custos econômicos e ambientais, ocasionando muitas vezes danos irreversíveis. Certamente vincular as metas das áreas econômica e social com a ambiental é um dos maiores desafios das políticas públicas desse século.

Em relação à compensação ambiental especificamente, destaca-se que a criação de uma metodologia para definir o valor do meio ambiente é algo extremamente complexo e multidisciplinar, portanto é necessário considerar essa complexidade para não se realizar críticas frívolas. Além disso, independentemente do valor destinado estabelecido por esse instrumento e a forma como é estabelecido, frisa-se que os impactos ambientais das intervenções antrópicas podem ser mitigados, mas não evitados, portanto medidas proibitivas severas nem sempre são as melhores soluções por muitas vezes impulsionam ações ilegais.

Da mesma maneira, é preciso enfatizar que nem tudo pode ser simplesmente compensado, portanto a compensação ambiental não pode ser simplesmente utilizada para aprovar qualquer atividade ou projeto (TORRESAN e LORANDI, 2008). Por isso, o planejamento ambiental deve-se fundamentar na interação e integração dos sistemas que compõem o ambiente, estabelecendo as relações entre os sistemas ecológicos e os processos da sociedade, das necessidades socioculturais a atividades e interesses econômicos, visando manter a máxima integridade possível dos seus elementos componentes (SANTOS, 2004).

Esse instrumento necessita obviamente prezar pela preservação e/ou conservação do meio ambiente, mas também pela eficiência econômica dos grandes projetos infraestruturais do país. Para tanto, as políticas ambientais precisam ser encaradas como elementos constitutivos e delineadores do desenvolvimento, sendo fundamentais para uma coerente gestão ambiental do território.

Apesar do Decreto atual estar em vigor há quase cinco anos, o imbróglio em relação a metodologia considerada adequada para todas as partes interessadas parece distante de se encerrar, possivelmente as alterações no método de cálculo da compensação ambiental ocorrerão a partir simplesmente de decisões judiciais, ou seja, a valoração do meio ambiente nesse caso ainda é uma questão debatida majoritariamente na esfera judicial quando deveria ser algo extremamente amplo e multidisciplinar

Outras abordagens para a análise e debate técnico também são fundamentais, através do estudo sobre a eficácia do mecanismo, visando garantir um mínimo de conservação aos ativos ambientais afetados pelos empreendimentos e deixando claro quais são suas influências sobre o território. Em um contexto econômico favorável, bilhões de reais estão sendo investidos em infraestruturas, as quais geram e gerarão significativos impactos ambientais pelo território que necessitam ser coerentemente gerenciados visando mitigá-los e compensá-los. 
O crescimento econômico não deve ocorrer a todo custo, é preciso garantir um desenvolvimento sustentável e, acima de tudo, coerente com perspectivas de longo prazo, sendo as questões que envolvem as compensações ambientais apenas um ponto dessa complexa conjuntura.

É curioso e intrigante refletir que este é um instrumento inserido diretamente na contradição entre o crescimento econômico e a proteção ambiental, pois a soma de recursos direcionados só ocorre no momento que há intervenções no meio ambiente, ou seja, quanto maior o montante de recurso disponível para o uso em medidas ambientais maiores são as intervenções no próprio ambiente.

Portanto, é necessário refletirmos sobre a forma como esse instrumento está estabelecido, pois o mesmo pode contribuir para aprovação de intervenções ambientais que estão em sentido oposto aos seus objetivos preservacionistas e/ou conservacionistas e que contribuirão para graves consequências no futuro.

De qualquer forma, em paralelo as essas reflexões, na atualidade é um mecanismo que envolve uma relevante soma de recursos que necessitam ser avaliados e despendidos de forma eficaz, pois é preciso que haja compensações de fato não apenas na esfera administrativa e jurídica. Por isso, é imprescindível ampliarmos esse espaço de discussão, afinal, as compensações ambientais existem para que e para quem?

\section{AGRADECIMENTOS}

Agradecemos à Fundação de Amparo à Pesquisa do Estado de São Paulo - FAPESP.

\section{REFERÊNCIAS}

ACSELRAD, H. Discurso da sustentabilidade urbana. Revista Brasileira de Estudos Urbanos e Regionais. Campinas: Unicamp, n.1, maio, pp. 79-90, 1999.

BANCO MUNDIAL. Data 2013 - The World Bank. Disponível em: $<$ http://data.worldbank.org/indicator/ NY.GDP.MKTP.CD>. Acesso em: 15 junho 2014. BECHARA, E. Licenciamento e Compensação
Ambiental. São Paulo: Atlas, 2009.

BIELSCHOWSKY, R. Pensamento econômico brasileiro: o ciclo ideológico do desenvolvimentismo. Rio de Janeiro: Contraponto, 1995.

BORN, R. H.; TALOCCHI, S. "Compensações por Serviços Ambientais: sustentabilidade ambiental com inclusão social". In: BORN, R. H.; TALOCCHI, S. (orgs.). Proteção do capital social e ecológico: por meio de Compensações por Serviços Ambientais (CSA). São Paulo: Peirópolis, p. 27-45, 2002.

BRASIL. Balanço 4 anos (2007-2010) do Programa de Aceleração do Crescimento. $11^{\circ}$ balanço completo. Brasília: Comitê gestor do PAC, 2010.

BRASIL. PAC2: $10^{\circ}$ Balanço - 2014. Brasília: Comitê gestor do PAC, 2014.

BRESSER-PEREIRA, L. C. Desenvolvimento e crise no Brasil. São Paulo: Ed. Brasiliense, 1975 [1968].

CMMAD - COMISSÃO MUNDIAL SOBRE O MEIO AMBIENTE E O DESENVOLVIMENTO. Nosso futuro comum: Comissão Mundial sobre Meio Ambiente e Desenvolvimento. Rio de Janeiro: Editora da Fundação Getúlio Vargas, 1991 [1987].

DOMingues, J. M.; CARNEIRO, J. S. A. A Compensação Ambiental prevista pelo Sistema Nacional de Unidades de Conservação (SNUC): a ADI $n^{\circ} 3.378$ e o Decreto $n^{\circ} 6.848 / 09$. Revista Direito GV 12. São Paulo, 6 (2), Jul-Dez, p. 493502, 2010. DOI:http://dx.doi.org/10.1590/S180824322010000200007

FARIA, I. D. Compensação ambiental: os fundamentos e as normas; a gestão e os conflitos. Brasília: Conleg, Consultoria Legislativa do Senado Federal. Textos para discussão $\mathrm{n}^{\circ} 43$, julho, 2008.

FREY, K. A dimensão político-democrática nas teorias de desenvolvimento sustentável e suas implicações para a gestão local. Ambiente \& Sociedade, Campinas, n. 9, dez, 2001. DOI:http://dx.doi. org/10.1590/S1414753X2001000900007 
FURTADO, C. Formação Econômica do Brasil. Rio de Janeiro: Fundo de Cultura, 1959.

GIASSON, M. M.; CARVALHO, S. H. C. Mecanismo de compensação ambiental federal no Brasil: impactos negativos e os recursos revertidos para unidades de conservação. $2^{\mathrm{a}}$ Conf. da REDE de Língua Portuguesa de Avaliação de Impactos e $1^{\circ}$ Congresso Brasileiro de Avaliação de Impacto. São Paulo, 2012.

GUIMARÃES, R. P. A ética da sustentabilidade e a formulação de políticas de desenvolvimento. In: VIANA, G.; SILVA, M.; DINIZ, N. (Orgs). O Desafio da Sustentabilidade: um debate socioambiental no Brasil. São Paulo: Fundação Perseu Abramo, pp. 43-71, 2001.

HOUAISS. Dicionário da Língua Portuguesa. Rio de Janeiro: Ed. Objetiva, 2009.

IBAMA - INSTITUTO BRASILEIRO DO MEIO AMBIENTE E DOS RECURSOS NATURAIS RENOVÁveIS. Guia de Procedimentos do Licenciamento Ambiental Federal. Brasília: Ibama, 2002.

ICMBIO - INSTITUTO CHICO MENDES. Compensação Ambiental. Disponível em: $<$ http:// www.icmbio.gov.br/portal/o-que-fazemos/ compensacao-ambiental.html $>$. Acesso em: 05 abril 2014

ISA - INSTITUTO SOCIOAMBIENTAL. ONGs vão ao STF para derrubar nova regra sobre compensação ambiental. Disponível em: <http://site-antigo. socioambiental.org/nsa/detalhe? $\mathrm{id}=2916>$. Acesso em 28 maio 2014.

LITTLE, P. E. Os desafios da política ambiental no Brasil. In: LITTLE, P. E. Políticas Ambientais no Brasil: análises, instrumentos e experiências. Brasília: IIEB, p.13-21, 2003.

MASSARDIER, G. Politiques et action publiques. Paris: Armand Colin, 2003.
MARTINEZ-ALLER, J. O ecologismo dos pobres: conflitos ambientais. São Paulo: Contexto, 2007.

MELlO, N. A. Políticas territoriais na Amazônia. São Paulo: Annablume, 2006.

MELLO-THÉRY, N. A. Território e gestão ambiental na Amazônia. São Paulo: Annablume, 2011.

MMA - MINISTÉRIO DO MEIO AMBIENTE. Programa Nacional de Capacitação de gestores ambientais: licenciamento ambiental. Brasília: MMA, 2009.

MONTIBELLER-FILHO, G. $O$ mito do desenvolvimento sustentável: meio ambiente e custos sociais no moderno sistema produtor de mercadorias. 3 ed. Florianópolis: UFSC, 2008.

MOREIRA, I. V. D. Avaliação de Impacto Ambiental - instrumento de gestão. Cadernos Fundap, São Paulo, ano 9, n. 16, jun., p. 54-63, 1989.

MOTA, J. A. et al. A valoração da biodiversidade: conceitos e concepções metodológicas. In: MAY, P. H. Economia do meio ambiente: teoria e prática. Rio de Janeiro: Elsevier, 2 ed., p. 265-288, 2010.

NORDAS, R.; GLEDITSCH, N. P. Climate change and conflict. Political Geography, v. 26, I, pp. 627638, 2007. DOI:10.1016/j.polgeo.2007.06.003

ORTIZ, R. A. Valoração Econômica Ambiental. In: MAY, P. H.; LUSTOSA, M. C.; VINHA, V. (orgs.). Economia do meio ambiente: teoria e prática. Rio de Janeiro: Elsevier, p. 81-100, 2003.

PAGNOCCHESCHI, B.; BERNARDO, M. Política Ambiental no Brasil. In: STEINBERGER, M. (Org.). Território, ambiente e políticas públicas espaciais. Brasília: LGE. p. 101-123, 2006.

PAQUEROT, S. Le droit international et la coopération dans le domaine de l'eau: enjeux et défis dans les Amériques. VertigO - la revue électronique em sciences de l'environnement. Hors-série 2, sep. 2005. 
PEARCE, D; MARKANDYA, A; BARBIER, E. Blueprint for a Green economy. 6. ed, London: Earthscan Publications Limited, 1992 [1989].

PINTO JÚNIOR, H. Q. (coord.). Perspectivas do investimento em infraestrutura. Projeto PIB Perspectivas do investimento no Brasil, v. 1, Rio de Janeiro: Synergia, 2010.

RAFFESTIN, C. Por uma geografia do poder. São Paulo: Editora Ática, 1993 [1980].

RIBEIRO, W. C. A tradição e os novos paradigmas. In: RIBEIRO, W. C. A ordem ambiental internacional. São Paulo: Contexto, 2001, p. 17-38.

RIBEIRO, W. C. O Brasil e a Rio +10. Revista do Departamento de Geografia. São Paulo: USP, v. 15, 2002, p. 37-44.

RIBEIRO, W. C.; SANT'ANNA, F. M. Governança da ordem ambiental internacional. In: RIBEIRO, W. C. (org.). Governança da ordem ambiental internacional e inclusão social. São Paulo: Annablume, 2012, p. 45-68.

ROMEIRO,A. R. Desenvolvimento sustentável: uma perspectiva econômico-ecológica. Estudos avançados, São Paulo, v. 26, n. 74, p. 65-92, 2012. DOI:http:// dx.doi. org/10.1590/S0103-40142012000100006

SACHS, I. Caminhos para o desenvolvimento sustentável. Rio de Janeiro: Editora Garamond, 2000. SACHS, I. Desenvolvimento includente, sustentável, sustentado. Rio de Janeiro: Editora Garamond, 2004.

SACHS, I. Rumo à ecossocioeconomia: teoria e prática do desenvolvimento. São Paulo: Cortez, 2007.

SÁNCHEZ, L. E. Avaliação de impacto ambiental: conceitos e métodos. São Paulo: Oficina de Textos, 2008.

SANTOS, B. O Norte, o Sul e a Utopia. In: SANTOS. B. Pela mão de Alice: o social e o político na pósmodernidade. São Paulo: Cortez, 1995, p. 281-348.
SANTOS, R. F. Planejamento Ambiental: teoria e prática. São Paulo: Oficina de Textos, 2004.

SPOSITO, E. S. Território, logística e mundialização do capital. In: SPOSITO, E. S. (Org.). Dinâmica econômica, poder e novas territorialidades. Presidente Prudente. GAsPERR/UNESP, p. 99-113, 1999.

STF - SUPREMO TRIBUNAL FEDERAL. Glossário Jurídico. Disponível em: <http://www.stf.jus.br/ portal $/$ glossario/verVerbete.asp?letra $=$ S\&id $=218>$ Acesso em 03 maio 2014.

TORRESAN, F. E.; LORANDI, R.. A methodological proposal for quantifying environmental compensation through the spatial analysis of vulnerability indicators. Brazilian Archives of Biology and Technology, Curitiba, v. 51, n.3, june, 2008. DOI: http:// dx.doi.org/10.1590/S1516-89132008000300026

TOLMASQUIM, M. T. Perspectivas e planejamento do setor energético no Brasil. Estudos Avançados, São Paulo, v. 26, n. 74, p. 247-260, 2012.

VEIGA, J. E. Desenvolvimento Sustentável: o desafio do século XXI. Rio de Janeiro: Editora Garamond, 2005.

VEIRET, Y; RICHEMOND, N. O risco, os riscos. In: VEIRET, Y. (org.). Os riscos. São Paulo: Contexto, 2007, p. 23-46.

VIEIRA, L.; CADER, R. A política ambiental na década 2002-2012. In: SADER, E. (org.). 10 anos de governos pós-liberais no Brasil: Lula e Dilma. São Paulo: Boitempo; Rio de Janeiro: Flacso Brasil, p. 225-238, 2013. 


\section{ERRATA 01:}

No artigo <Compensação ambiental: da contradição à valoração do meio ambiente no Brasil>, com número de DOI: < http://dx.doi.org/10.1590/1982-451320150202>, publicado no periódico $<$ Revista Sociedade\&Natureza $>$, $<$ vol. $27>(<$ num. $2>$ ): $<209-222>$, na $<$ pagina $209>$ onde se lia:'<Rafael de Oliveira Fonseca $>$ 'leia-se:'<Rafael Oliveira Fonseca $>$ ' 